\title{
MUTABILIDADES NO WEBJORNALISMO E A CONSOLIDAÇÃO DE UM NOVO FORMATO DE REPORTAGEM DIGITAL
}

\author{
Mutabilities in webjournalism and the consolidation of a new digital \\ report format
}

Mutaciones en webperiodismo y la consolidación de un nuevo formato del reportaje digital

Liliane de Lucena Ito

Doutora em Comunicação pela Unesp

lilianedelucena@gmail.com

\section{Resumo}

Neste artigo, realiza-se uma revisão acerca das mutabilidades do jornalismo, em especial do webjornalismo, e seus reflexos positivos, como a emergência de novos formatos de apresentação de conteúdo. O foco de análise é a série de reportagens digitais TAB, do portal Uol. O trabalho se ampara em pesquisa bibliográfica e documental. Os resultados relacionam a evolução do webjornalismo ao surgimento e à consolidação de novos formatos jornalísticos, como as vertentes da reportagem: a grande reportagem multimídia, a reportagem paralaxe e/ou a reportagem multimídia interativa, que herdam características da grande reportagem impressa, mas apresentam diferenciais importantes, como a interatividade, a hipertextualidade e a multimidialidade.

Palavras-chave: Webjornalismo. Reportagem digital. TAB.

\begin{abstract}
In this article, a review is made about the mutabilities of journalism, especially webjournalism, and its positive effects, such as the emergence of new content presentation formats. The focus of analysis is the series of digital reports TAB, of the portal Uol. The work is based on bibliographical and documentary research. The results relate the evolution of webjournalism to the emergence and consolidation of new journalistic formats, such as the reporting aspects: the large multimedia report, the parallax report and / or the interactive multimedia report, which inherit characteristics of the large print report, but present important differences, such as interactivity, hypertextuality and multimedia.
\end{abstract}

Key words: Webjournalism. Digital report. TAB. 


\section{Resumen}

En este artículo, se llevó a cabo una revisión de las mutaciones del periodismo, especialmente el webperiodismo, y su impacto positivo, como la aparición de nuevos formatos de presentación de contenido. El foco de análisis es la serie de reportajes digitales TAB, del portal UOL. El trabajo usa la investigación bibliográfica y documental. Los resultados se refieren a la evolución del webperiodismo y la aparición y consolidación de nuevos formatos periodísticos, como el gran reportaje multimedia, el reportaje paralaje y / o el reportaje multimedia interactivo, heredando características del gran reportaje impreso, pero con diferencias importantes tales como la interactividad, hipertextualidad y multimedialidad.

Palabras clave: Webperiodismo. Reportaje digital. TAB.

\section{INTRODUÇÃO}

No campo do jornalismo, o advento da Sociedade em Rede (CASTELLS, 1999) e a convergência midiática e cultural (JENKINS, 2008) transformaram notavelmente a esfera da produção, cujas articulações são vistas, entretanto, não apenas nos arranjos produtivos, mas também na apresentação da notícia e em formas, até então inéditas, de consumo das mesmas. Com a popularização da internet, expande-se de forma contundente o acesso gratuito à informação jornalística em ambientes digitais, on-line e em rede, em detrimento aos meios tradicionais, como o impresso, o que veio a estabelecer crises econômicas sem precedentes nas empresas de mídia - forçando-as a investirem tempo e dinheiro na busca por novos modelos de negócio (COSTA, 2014).

Vale ressaltar que as mutabilidades observadas no jornalismo parecem estar longe de se dissiparem, encontrando-se, na verdade, em pleno andamento. Ainda no início desta década, Pereira e Adghirni (2011) apontam algumas delas em três searas distintas: a da produção noticiosa, cada vez mais vinculada a uma cobertura em tempo real dos acontecimentos (devido à natureza on demand do webjornalismo); o perfil do jornalista, que também se transforma, já que muitos saem das redações para trabalhar em assessorias, além do enfrentamento de questões complexas como a precarização das condições de trabalho; e, por fim, transformações relacionadas às novas relações com os públicos, cada vez mais dedicados à autopublicação e abertos a novos hábitos de consumo de informação que vão além dos oferecidos nos formatos tradicionais.

Quase ao final da década, ainda que diante de contextos bem recentes, estudos atuais sobre as mesmas questões corroboram a ideia de que o momento ainda é de instabilidade e 
mudança. Bell et al (2017), por exemplo, atentam para o fato de que sites de redes sociais, como o Facebook e o Twitter, têm ascendido ao posto de publicadores, ao lado da legacy media, em outras palavras, empresas jornalísticas tradicionais. Isso ocorre porque cada vez mais usuários do mundo inteiro buscam se informar no ambiente interno de suas mídias sociais, ao invés de navegarem até o site oficial dos veículos noticiosos. Já Anderson (2017) sustenta haver um aumento considerável no consumo de jornalismo via dispositivos móveis, impactando a esfera da produção, voltada agora a iniciativas que valorizem a comunicação instantânea, conversacional e curta ou, por outro lado, ao jornalismo visual adaptado ao mobile, como é o caso dos investimentos massivos do jornal The New York Times que criou, nos últimos anos, equipes inteiramente dedicadas à produção de vídeos de realidade virtual (ANDERSON, 2017).

Naturalmente, as alterações empreendidas no consumo vêm a instaurar imperativos diversos tanto ao setor produtivo quanto ao perfil do jornalista, que necessita se reinventar e adquirir novos saberes, mesmo que em níveis básicos, como conhecer algumas técnicas de programação ou lidar com fórmulas estatísticas para analisar grandes volumes de dados, o que evidencia, então, a articulação existente entre as searas analisadas em Pereira e Adghirni (2011): rotinas produtivas; perfil do jornalista e público/consumo. Na visão dos autores, o cenário atual do jornalismo implica mudanças de caráter estrutural, ou seja, transformações de ordem profunda, capazes de alterar de maneira radical a prática, a definição e o reconhecimento simbólico de uma determinada atividade (no caso, o fazer jornalístico).

Sob tal perspectiva, por meio de pesquisa bibliográfica e documental, o trabalho em questão tem por objetivo debater as mutabilidades do jornalismo feito na e para a publicação na Internet, uma vez que se considera este o meio pelo qual necessariamente passa o presente e o futuro do jornalismo. Num primeiro momento, discute-se a ideia de que o próprio webjornalismo encontra-se em constante transformação para, num segundo momento, ajustar o foco para a consolidação de um novo formato de reportagem digital como parte do processo de evolução dos produtos jornalísticos na web. Para tanto, é realizada análise empírica, em nível exploratório, cujo objeto é a série de reportagens $\mathrm{TAB}^{1}$, do portal Uol. Os resultados indicam que a reportagem digital articula mutabilidades existentes no processo produtivo, no perfil dos profissionais envolvidos e também no próprio consumo, mais interativo e potencialmente mais imersivo em comparação à reportagem publicada em suportes predecessores, como o impresso ou o televisivo, por exemplo.

\footnotetext{
${ }^{1}$ Disponível em: < tab.uol.com.br >. Acesso em: 29 ago. 2018.
} 


\section{WEBJORNALISMO EM MUTAÇÃO}

Canavilhas (2001) ao propor o termo "webjornalismo" como um jornalismo feito para a web, com novas narrativas, que integrem elementos multimidiáticos, interativos e hipertextuais, aponta que este não deve seguir a técnica redacional de pirâmide invertida, canônica no jornalismo impresso. Assim, quem constrói o caminho da leitura é o próprio leitor. Esta é uma das mudanças que evidenciam que, da mesma maneira que se transforma o processo de produção, altera-se também a forma de consumo.

O autor, assim como outros acadêmicos portugueses, defende a utilização da terminologia "webjornalismo" em contraponto a outros termos, como jornalismo digital, ciberjornalismo ou mesmo jornalismo on-line ${ }^{2}$. Sob a mesma nuvem semântica, com variações defendidas de autor para autor, "tais nomenclaturas, desde a década de 90, vêm auxiliando na demarcação de um novo tipo de jornalismo, em um ambiente igualmente novo para publicar e fazer circular suas informações sem limitações de tempo e espaço [...]”, esclarece Barbosa (2013, p. 38).

Jorge (2008), que adota a terminologia "jornalismo digital", nos coloca diante da ideia da notícia em mutação: além de deixar de ter uma forma física, no papel, a notícia liga-se por meio de lexias hipertextuais, e tem a velocidade incorporada na produção. A relação do jornalista com o público passa a ser bastante diferente da anterior, em que o jornalista produzia e o público, passivo, consumia. Há então um embaralhamento visível entre emissores e receptores, uma vez que estes últimos, potencialmente, são também produtores de informação.

A evolução do jornalismo, desde muito antes de algum tipo de convergência midiática, sempre esteve ligada à evolução dos meios de difusão (CANAVILHAS, 2006). A separação proposta por Pavlik (2001) acerca de diferentes estágios do jornalismo on-line (termo utilizado pelo autor), vem ao encontro do que afirma Canavilhas, já que cada um está relacionado às possibilidades técnicas da Internet em seus diferentes momentos. O primeiro estágio seria aquele em que apenas se republicava a versão impressa dos jornais nas telas do computador. No segundo, havia melhorias nos sites, com conteúdos criados originalmente para a web, com o uso de hiperlinks, algumas opções de interatividade e multimidialidade,

\footnotetext{
${ }^{2}$ Neste trabalho, será utilizado, preferencialmente, a nomenclatura "webjornalismo", que também é adotada por diversos pesquisadores brasileiros. Entretanto, cada pesquisador(a) terá o termo defendido por ele(a) quando ocorrer a necessidade de citação referencial.
} 
além da possibilidade de customização, mesmo que limitada. O terceiro estágio do jornalismo on-line, segundo Pavilk (2001), é aquele no qual irá emergir conteúdo noticioso verdadeiramente original, desenhado de forma específica para a publicação na Internet. A notícia é mais contextualizada, as narrativas são imersivas, e o usuário pode realizar a navegação por conteúdos relacionados de forma alinear.

No Brasil, Mielniczuk (2003), é uma das pesquisadoras que utiliza o termo “webjornalismo". Em sua tese de doutorado, defende, a partir da ideia de gerações, que a terceira geração do webjornalismo é o momento em que a interatividade, a customização de conteúdo, a hipertextualidade, a multimidialidade, a memória e a atualização contínua estão presentes. Tal fase só foi possível graças ao avanço da estrutura técnica, à transmissão mais rápida de sons e imagens, e à expansão no número de usuários, o que fez com que as empresas investissem mais no setor.

Barbosa (2008), assim como acadêmicos espanhóis que se dedicam ao estudo do tema, opta pela adoção do termo "ciberjonalismo". Em suas investigações, observa a evolução do ciberjornalismo em fases que sucedem a terceira geração. Na quarta fase, algumas das características do ciberjornalismo são, segundo a autora:

[...] consolidação das bases de dados como estruturantes da atividade jornalística e como agentes singulares no processo de convergência jornalística; equipes mais especializadas; desenvolvimento de sistemas de gestão de conteúdos (SGC) mais complexos e baseados preponderantemente em softwares e linguagens de programação com padrão open source, formato XML (eXtensible Markup Language), algoritmos; acesso expandido por meio de conexões banda larga; proliferação de plataformas móveis; consolidação do uso de blogs; ampla adoção de recursos da Web 2.0; incorporação de sistemas que habilitam a participação efetiva do usuário na produção de peças informativas; produtos diferenciados criados e mantidos de modo automatizado; sites dinâmicos; narrativas multimídia [...]. (BARBOSA, 2008, p. 9).

Barbosa (2008) lembra que nem todos os produtos jornalísticos digitais possuem as características reunidas em sua completude - algo que depende obviamente da estrutura e do investimento de cada empresa. Entretanto, os mais inovadores apresentam projetos ou mesmo grande parte de seu conteúdo que podem ser encaixados nesta quarta geração do webjornalismo. A seu ver, já é possível classificar uma quinta geração do jornalismo nas 
redes digitais ${ }^{3}$. Entre outras características, pode-se citar a mobilidade como um dos elementos balizadores do atual momento:

Neste contexto, as mídias móveis, especialmente smartphones e tablets, são os novos agentes que reconfiguram a produção, a publicação, a distribuição, a circulação, a recirculação, o consumo e a recepção de conteúdos jornalísticos em multiplataformas. As mídias móveis são também propulsoras de um novo ciclo de inovação, no qual surgem os produtos aplicativos (apps) jornalísticos para tablets e smartphones. (BARBOSA, 2013, p. 42)

Alguns pesquisadores defendem que até mesmo uma das práticas mais comuns nas redações, o gatekeepig, estaria evoluindo para uma segunda prática (pois podem ser concomitantes), o chamado gatewatching (BRUNS, 2005), que não mais seria uma função que seleciona o mais relevante num universo de informações que devem ser encaixadas em um limitado espaço físico (o que ocorre no gatekeeping). Na virtualidade, espaço não é exatamente um problema e, assim, o gatewatching seria uma nova postura de jornalistas/editores que, na web, possuem muito mais espaço disponível para publicar e, por isso, atuam como observadores da rede, não deixando passar informações relevantes que emergem a todo o momento de diversos ambientes on-line. Neste processo, os gatewatchers observam publicações na concorrência ou em outras fontes (como blogs e mídias sociais, por exemplo) com o objetivo de identificar o que merece ser publicado, no momento em que estiver disponível na internet.

Barsotti (2014), ao realizar um estudo empírico baseado em observação participante nas redações dos sites dos jornais $O$ Globo e Extra, defende que, além de gatekeeper, o jornalista/editor de veículos on-line também exerce a função de gatewatcher, um "vigia" da concorrência e de fontes (às vezes primárias) de informação cujo objetivo é não deixar de publicar também algo que todos estão vendo, como por exemplo, um viral. Essa preocupação ocorre muito por conta do fato de o espaço no site, inclusive nas homepages, ser muito mais flexível em relação ao jornal impresso. "Embora também haja limitação de espaço nas capas dos sites, ela é mínima [...]. Enquanto na primeira página de $O$ Globo é possível encaixar, em média, 15 chamadas, na capa do site há espaço para cerca de 55”. (BARSOTTI, 2014, p. 5)

Se espaço não é exatamente uma questão, a ponto de originar uma nova função do editor, a do gatewatcher, por que não investir em formatos jornalísticos como o da grande

\footnotetext{
${ }^{3}$ Além de "ciberjornalismo", Barbosa (2013) tem utilizado, mais recentemente, a nomenclatura "jornalismo em redes digitais".
} 
reportagem, rara muito por conta da questão do espaço físico nos jornais e nas revistas? Uma vez que não há limitação no tamanho do texto, ao mesmo tempo em que é possível adicionar todos os recursos multimidiáticos (imagens, sons, vídeos, animações, elementos interativos) que enriquecem ainda mais a narrativa, o ciberespaço pode abrigar novos formatos jornalísticos, mais instigantes e, por que não, completos. O fato é que muitas das características e práticas do webjornalismo, na atualidade, estão ainda relacionadas à velocidade da informação e à disponibilização da notícia em diversos suportes, num formato fragmentado, de texto curto e sintético, recheado de hiperlinks que direcionam a outras webnotícias fragmentadas.

Entretanto, desde 2012, começam a surgir exemplos de textos jornalísticos que, na contramão da webnotícia, aprofundam e requerem uma leitura mais concentrada, mas nem por isso contemplativa, uma vez que recursos interativos também estão presentes. Segundo Longhi (2014), há um ponto de virada na produção de textos jornalísticos aprofundados, de grande número de caracteres, ilustrados e/ou complementados por vídeos, áudio e animações, denominados pela autora como grande reportagem multimídia, "gênero específico do webjornalismo, herdeiro da grande reportagem do impresso" (LONGHI, 2014, p. 899). A grande reportagem multimídia é explorada por poucos veículos, geralmente aqueles que têm mais condições financeiras para investir no formato, como é o caso dos norte-americanos The New York Times e The Washington Post, além do britânico The Guardian e, no Brasil, dos jornais $O$ Estado de S. Paulo, Folha de S. Paulo e O Globo.

Do ponto de vista da produção, a grande reportagem multimídia só é possível se realizada de maneira integrada entre vários profissionais, uma vez que são utilizados elementos de texto e imagem, além de áudio, vídeo, infográficos animados e recursos interativos, como enquetes, jogos e testes, que exigem programações específicas. Apesar dos desafios, diversos veículos têm enxergado a necessidade de oferecer conteúdo diferenciado e especial aos seus leitores, a fim de não se limitar a apenas uma matriz midiática e também pelo fato de que tais inovações podem vir a se tornar fontes de receita no ambiente digital, como visto em Ventura e Ito (2017).

Como se pode imaginar, são muitas as dificuldades enfrentadas por jornalistas do impresso que trabalham também com material multimídia. Uma delas é a corrida contra o tempo, principalmente para aqueles que precisam fazer malabarismos para entregar o material no prazo da edição em papel além de ter que produzir conteúdo extra, como vídeos, para o site do jornal. Lenzi (2012), ao entrevistar jornalistas do Diário Catarinense que, à época, viviam 
essa realidade, observou outros desafios relatados pelos próprios profissionais, como a falta de conhecimentos técnicos para operar equipamentos a fim de se chegar a um material de qualidade, além da dificuldade de ter de fazer mais de uma coisa ao mesmo tempo.

Entretanto, quando se trata de grande reportagem multimídia, totalmente pensada para ser publicada on-line, o que se pode notar, geralmente, é um processo diferenciado, com prazos maiores e equipes especiais, com jornalistas destacados para tais coberturas. Foi o caso da grande reportagem multimídia publicada em 2013 pela Folha de S. Paulo sobre Belo Monte, que levou 10 meses para ser finalizada e envolveu 15 profissionais para relatar a construção da hidrelétrica, de maneira interativa e aprofundada. A reportagem deu origem à série Tudo Sobre, que trouxe outros temas em formato de grande reportagem multimídia, como a crise hídrica e a ditadura militar brasileira.

Longhi (2014) propõe uma linha cronológica dos formatos noticiosos hipermidiáticos e defende que a grande reportagem multimídia só é possível graças aos avanços técnicos e ao estabelecimento da linguagem HTML5, pois esta possibilita design inovador, melhor navegação e imersão do usuário diante do conteúdo oferecido. Segundo a pesquisadora, é neste mesmo ponto em que começam a surgir as primeiras narrativas mais longas, com grande número de caracteres (o texto long form). A grande reportagem multimídia é, então, "definida por técnicas como o parallax scrolling ${ }^{4}$, ambientes e ferramentas como HTML5, CSS, narrativas imersivas e texto long form, dentre outras características inovadoras de design e informação". (LONGHI, 2014, p. 908)

Já Canavilhas (2014) refere-se a tal tipo de material jornalístico como "reportagem paralaxe" por defender ser adequado defini-la em relação à tecnologia utilizada. Para o autor, fazem parte desse gênero as reportagens em que, além do uso do parallax scrolling, existe uma “[...] navegação verticalizada e intuitiva, em conjunto com a plena integração de conteúdos multimídia" (CANAVILHAS, 2014, p. 8), algo que tornaria a leitura mais imersiva e envolvente, além de ser facilmente adaptável a diversos formatos de tela.

Ito e Ventura (2016), por sua vez, utilizam o termo "reportagem multimídia interativa”, uma vez que, segundo os autores, o mesmo considera as duas características principais do formato - multimidialidade e interatividade - e, ao mesmo tempo, é uma nomenclatura que está ligada não somente ao formato da grande reportagem, uma vez que determinados veículos têm apostado na publicação de narrativas mais enxutas.

\footnotetext{
${ }^{4}$ A fim de dar uma sensação ilusória de profundidade de campo, esta é uma técnica de design que usa elementos gráficos (fundos de tela, imagens e textos, por exemplo) sobrepostos em camadas que se movimentam em velocidades distintas conforme acontece a rolagem do cursor.
} 


\subsection{Reportagem em série: o TAB}

Oitavo site de maior audiência ${ }^{5}$ no Brasil, o portal Uol (uol.com.br), que pertence ao grupo Folha, segue, no geral, o modelo tradicional de webnotícia. Entretanto, desde outubro de 2014 o Uol publica a série de reportagens TAB, que ultrapassou, em novembro de 2017, a marca de 138 edições publicadas.

Dez pessoas, entre jornalistas, ilustradores, designers, produtores audiovisuais e desenvolvedores, estão envolvidas na produção de cada edição. Sua publicação acontece às segundas-feiras, com grande destaque, em tamanho e área, na homepage do Uol. A partir de terça-feira, a reportagem do TAB daquela semana passa a ter um destaque menor, figurando entre as últimas da página principal do portal.

O TAB é um exemplo de reportagem multimídia interativa (ITO, VENTURA, 2016) ou reportagem paralaxe (CANAVILHAS, 2014), por conta de sua narrativa ser menor em relação ao gênero grande reportagem multimídia (LONGHI, 2014). Entretanto, herda características da reportagem do impresso, como a apuração e a profundidade temática. Nas palavras de Lima (2009), a reportagem "é a ampliação do relato simples, raso, para uma dimensão contextual” (LIMA, 2009, p. 18). O autor nos lembra que, na reportagem, há um mergulho ainda maior nos fatos e no contexto, o que oferece ao jornalista uma grande liberdade em relação às amarras do lead e da pirâmide invertida, por exemplo.

Assim, em sua dimensão textual, as narrativas do TAB possuem, em geral, de 10 a 25 mil caracteres. Entre os temas abordados, percebe-se uma inclinação a assuntos discutidos amplamente na imprensa ou nas redes sociais, como os exemplos das reportagens sobre o treinamento dos policiais militares em São Paulo, o feminismo embutido na explosão do sertanejo feminino no País, além do drama dos refugiados internacionais. Entretanto, há também abordagens de temáticas específicas, como tecnologia (impressoras 3D, emojis, senhas), saúde (corrida, tipos de parto), ciência (genética, inconsciente), economia e consumo (lixo, água, economia compartilhada, moda), sexualidade/comportamento (transgêneros, feminismo) e religião (exorcismo).

Alguns dos assuntos abordados claramente se encaixam na categoria dos temas de longa duração (BENETTI, 2013), aqueles que, no jornalismo de revista, sobrevivem a demandas circunstanciais. Esta aproximação ao jornalismo de revista talvez ocorra por conta da segmentação temática do TAB, uma vez que, segundo o próprio Uol, o objetivo do mesmo

\footnotetext{
${ }^{5}$ Segundo dados do Alexa. Disponível em: < http://www.alexa.com/siteinfo/uol.com.br >. Acesso em: 28 nov. 2017.
} 
é oferecer conteúdo dinâmico, com abordagens criativas sobre temas provocativos. A proposta do TAB seria, então, a de prender a atenção do leitor e não apenas acumular cliques ${ }^{6}$. Entretanto, não é somente em relação aos temas abordados, segmentados por tais "polêmicas", que o TAB se assemelha ao jornalismo de revista. A linguagem, informal, leve e prazerosa, e sua característica visual marcante são outras aproximações notáveis. Em relação à linguagem, os textos do TAB são recheados por figuras de linguagem, construções que buscam uma aproximação junto ao leitor, além de títulos e subtítulos criativos. O excerto a seguir, extraído da edição 21 , é um exemplo:

\begin{abstract}
Você aí que anda meio depressivo no mundo corporativo, olhando discretamente para seu chefe por cima da baia, achando que ele anda pegando demais no seu pé... talvez você consiga amenizar esse sentimento incômodo ao conhecer o método de comando de um gestor que fez barulho recentemente, o senhor Uday Hussein. Com ele não tem papinho no café para tentar entender as necessidades de seu subordinado, nem qualquer brecha de diálogo. Não tinha, aliás. Com uma das cartilhas de administração mais sádicas que se tem notícia desde a Roma de Nero, o gerentão em questão afundou o seu negócio - e a si próprio. (FREITAS; ALMASRI, 2015, on-line)
\end{abstract}

Scalzo (2011) lembra que o texto de revista precisa de um "tempero a mais", pois “diferente do leitor de jornal, o [leitor] de revistas espera, além de receber a informação, recebê-la de forma prazerosa" (SCALZO, 2011, p. 76). Essa demanda pode ser semelhante no caso do leitor de uma grande reportagem multimídia: a leitura de um conteúdo aprofundado, com credibilidade jornalística, em linguagem fluida e layout especial.

Com relação aos layouts do $\mathrm{TAB}$, estes são sempre diagramados semelhantemente à estética de revista (e não a de jornal ou de webnotícia comum). Cada matéria é pensada para integrar texto e imagem, além de vídeo, animações, cores, tipografia, luz, texturas, criando, além de identidade para cada edição, uma experiência ao mesmo tempo interativa e sinestésica para o leitor.

Numa tentativa de delimitar características do jornalismo de revista, Benetti (2013) destaca dois elementos constitutivos do discurso que são essenciais também no caso das reportagens veiculadas pelo TAB: o dispositivo de autoridade (que seriam os elementos que atestam a seriedade da informação relatada) e o vínculo emocional.

\footnotetext{
${ }^{6}$ Disponível em: < http://noticias.uol.com.br/ultimas-noticias/redacao/2014/10/13/uol-lanca-o-tab-novo-projeto-editorialinterativo.htm >. Acesso em: 25 nov. 2017.
} 
Se o texto é mais fluido, se os títulos permitem os trocadilhos e os jogos de linguagem, se as ilustrações trazem o humor, se a sequência de leitura fornece a diversão, se as imagens carregam ambiguidades e se o processo de leitura é sensorial e prazeroso, então, de algum modo, o discurso precisa criar ancoragens de que está a tratar seriamente e de forma competente - de forma jornalística - daqueles assuntos tão interessantes [...]. Contudo, não basta ao leitor confiar na autoridade de quem enuncia; é preciso ter algum tipo de prazer na companhia daquele enunciador, estabelecendo um vínculo emocional. (BENETTI, 2013, p. 54)

As reportagens do $\mathrm{TAB}$, apesar da maior liberdade de linguagem e visual, sempre se apoiam em fontes habitualmente buscadas pela imprensa em seu dia a dia: especialistas no assunto, dados oficiais, pesquisas científicas de renome. Isso, de certa maneira, contribui para reforçar o dispositivo de autoridade, evidenciando que, apesar da leitura leve, trata-se de um material que fora estudado, pesquisado e interpretado por jornalistas. É possível notar, nos textos do $\mathrm{TAB}$, uma preocupação em oferecer ao leitor um aprofundamento temático tanto extensivo quanto intensivo, segundo a definição de Lima (2009), ou seja, há uma quantidade de informações que aumentam quantitativamente (extensivamente) a taxa de conhecimento do leitor sobre o tema (presente em dados numéricos, por exemplo) e também análises multiangulares sobre causas, consequências e desdobramentos acerca do assunto abordado que, por sua vez, garantirão o aumento informacional qualitativo (intensivo) sobre a questão.

Já em relação ao vínculo emocional, um dos elementos é a estética, que de certa forma incita o leitor a ir descobrindo o conteúdo, mesmo que extenso, uma vez que este é trabalhado em conjunto com estímulos visuais constantes (movimento, animações, cores, imagens de fundo). O layout do TAB é responsivo, ou seja, é planejado para se adaptar ao dispositivo que o leitor estiver utilizando (seja computador, smartphone, tablet ou outro aparelho).

Ainda sobre o layout, há também o vínculo formado pelo estímulo à interação do leitor. Na edição de número 15, cujo tema é o inconsciente humano, há três testes (denominados como "O Jogo das Cores" - Figura 1, "O Jogo do Inconsciente" - Figuras 2 e 3 e "Você é Intuitivo?") que exigem do leitor um esforço de pensamento, seja um exercício de cálculo numérico ou a reflexão sobre algum aspecto de sua própria personalidade. 


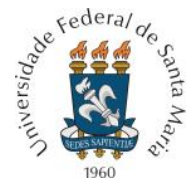

PROGRAMA DE PÓS-GRADUAÇÃO EM COMUNICAÇÃO DA UNIVERSIDADE FEDERAL DE SANTA MARIA

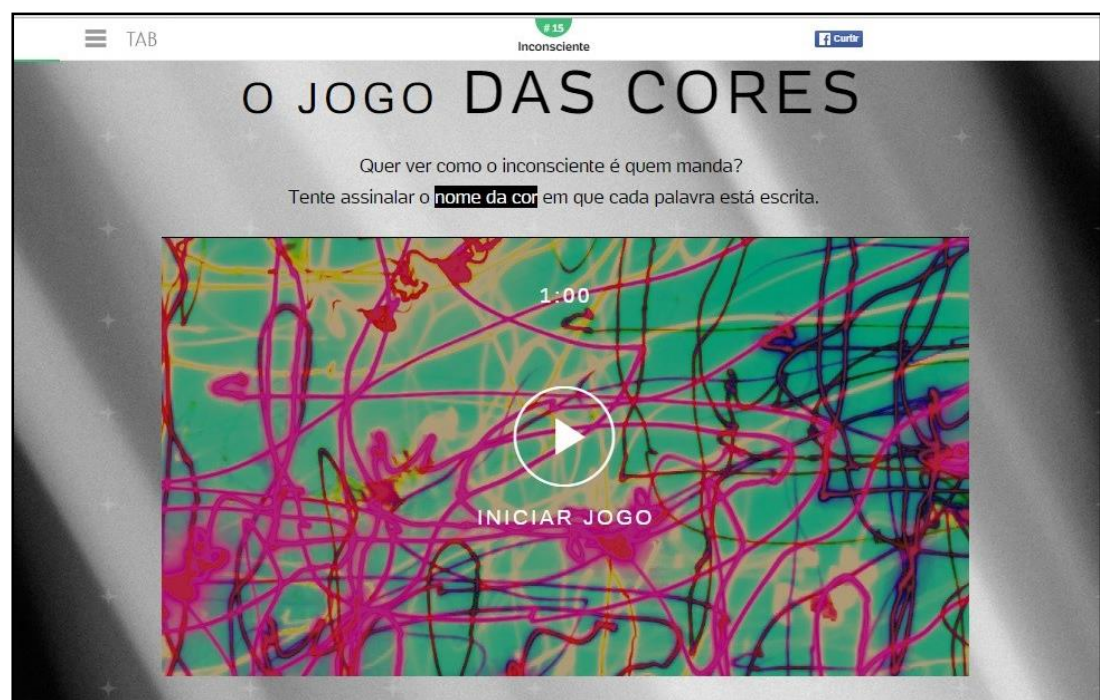

Figura 1. "Jogo das Cores": exemplo de recurso interativo presente na narrativa do TAB. Fonte: captura de tela

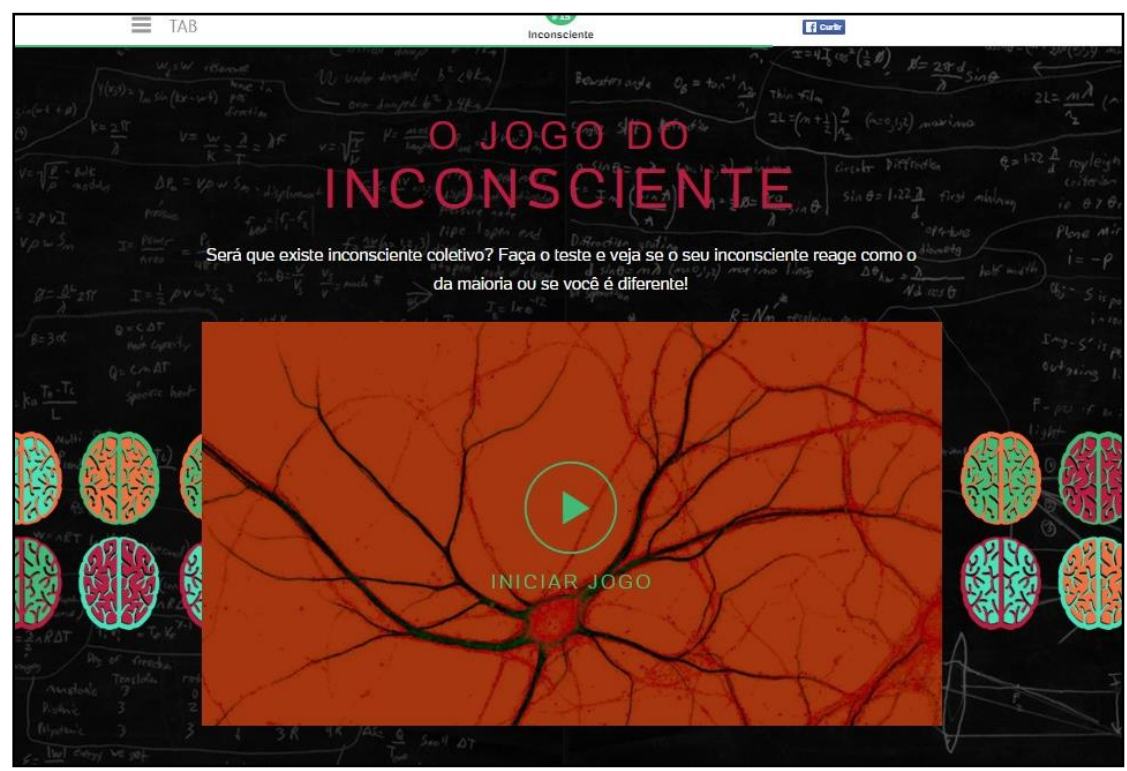

Figura 2. "O Jogo do Inconsciente" exige que o usuário faça contas mentalmente. Ao final, é feita a pergunta: "pense em uma ferramenta e uma cor".

Fonte: captura de tela 


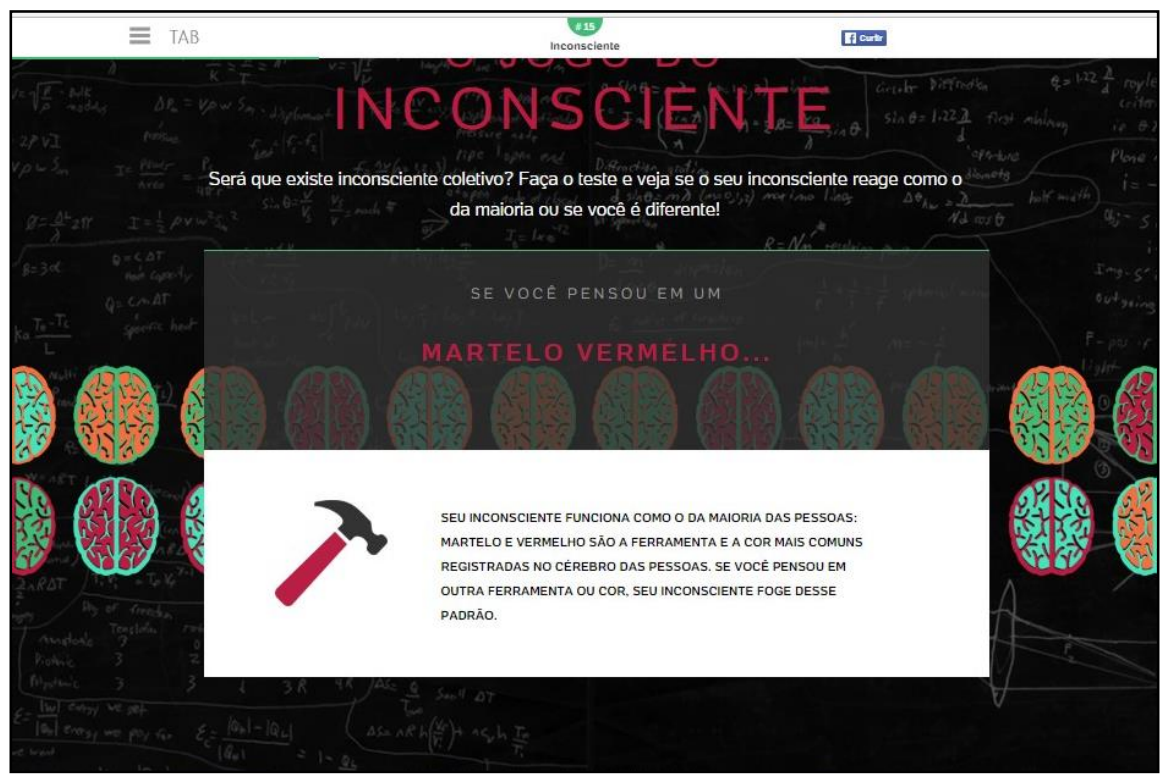

Figura 3. Na tela que se segue, é dada a resposta, vista na imagem em questão.

Fonte: captura de tela

Por sua vez, a edição de número 26, sobre transgêneros, inicia o assunto apresentando, no formato de storytelling, a trajetória de dois transgêneros brasileiros. Aqui, é possível notar o uso da hipertextualidade, uma das características do webjornalismo segundo Canavilhas (2001), como estruturadora da narrativa. A partir de cinco opções de links, o usuário é convidado a conhecer mais sobre a história de cada personagem - e boa parte do conteúdo é disponibilizada em audiovisual, o que demonstra o uso combinado de hipertextualidade e multimidialidade, uma vez que há vários links para os vídeos, que podem ser assistidos aleatoriamente ou mesmo em sequência (Figuras 4 e 5).

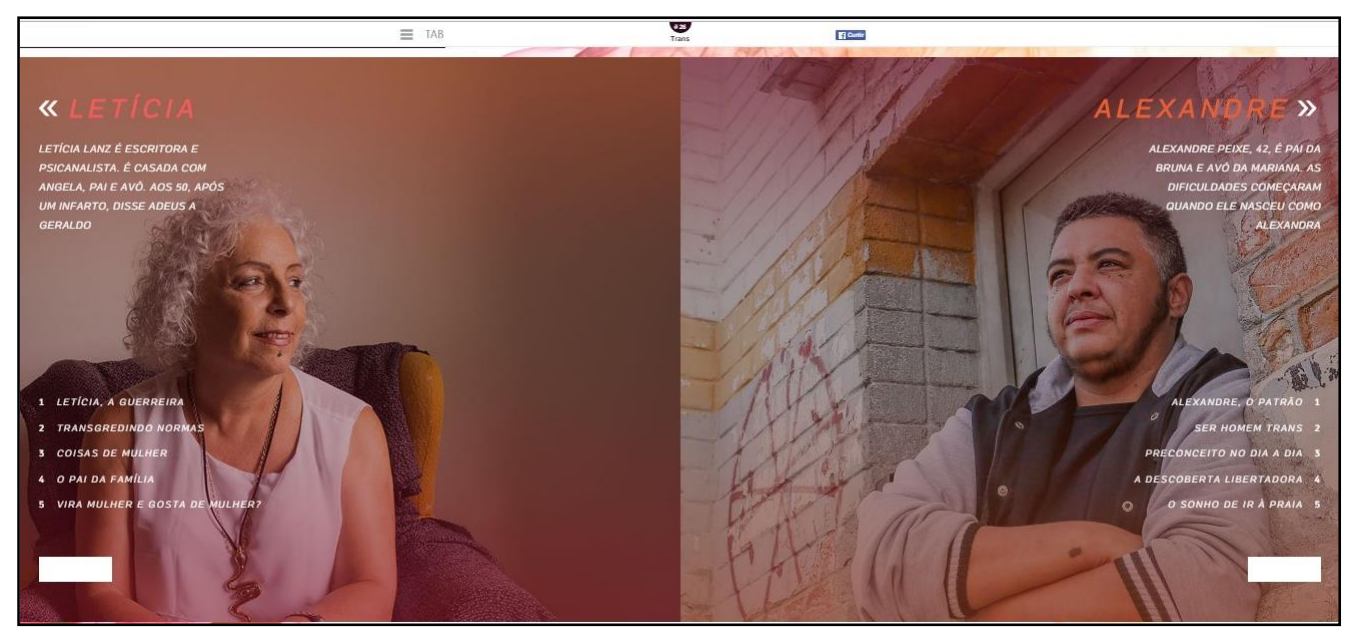

Figura 3. Estrutura narrativa da reportagem "Transgêneros" é baseada em hiperlinks. Fonte: captura de tela. 


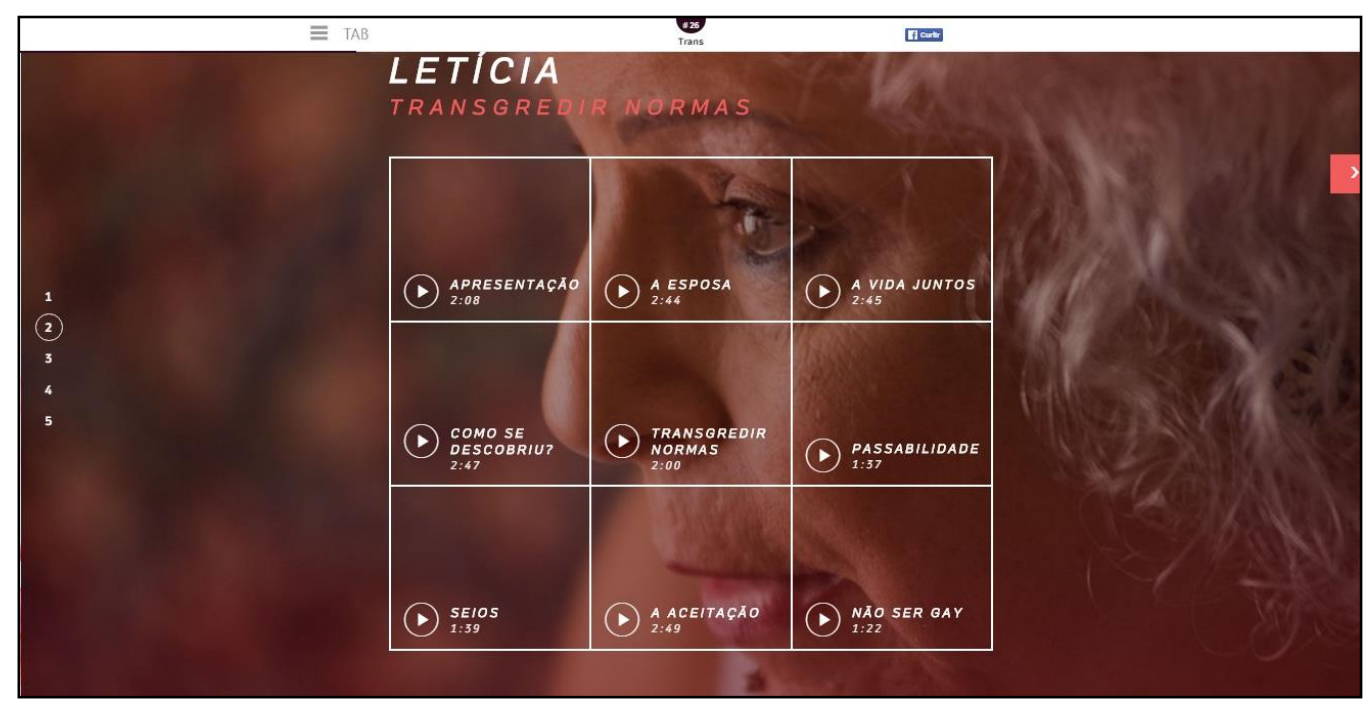

Figura 5. A partir da primeira escolha de ordem de leitura, novas possibilidades de percurso narrativo são reveladas ao usuário. Boa parte do conteúdo é audiovisual, como pode ser visto nesta imagem.

Fonte: captura de tela.

Por fim, ainda na mesma edição, a fim de explicar sobre todos os termos utilizados atualmente para a identificação do gênero (conforme a reportagem, são 12 no total), uma experiência interativa é oferecida ao leitor (Figura 6), que deve fazer uma combinação hipotética de três passos - escolher o sexo de um indivíduo atribuído no nascimento, depois o sexo com o qual se identifica e, por fim, o sexo pelo qual sente atração sexual.

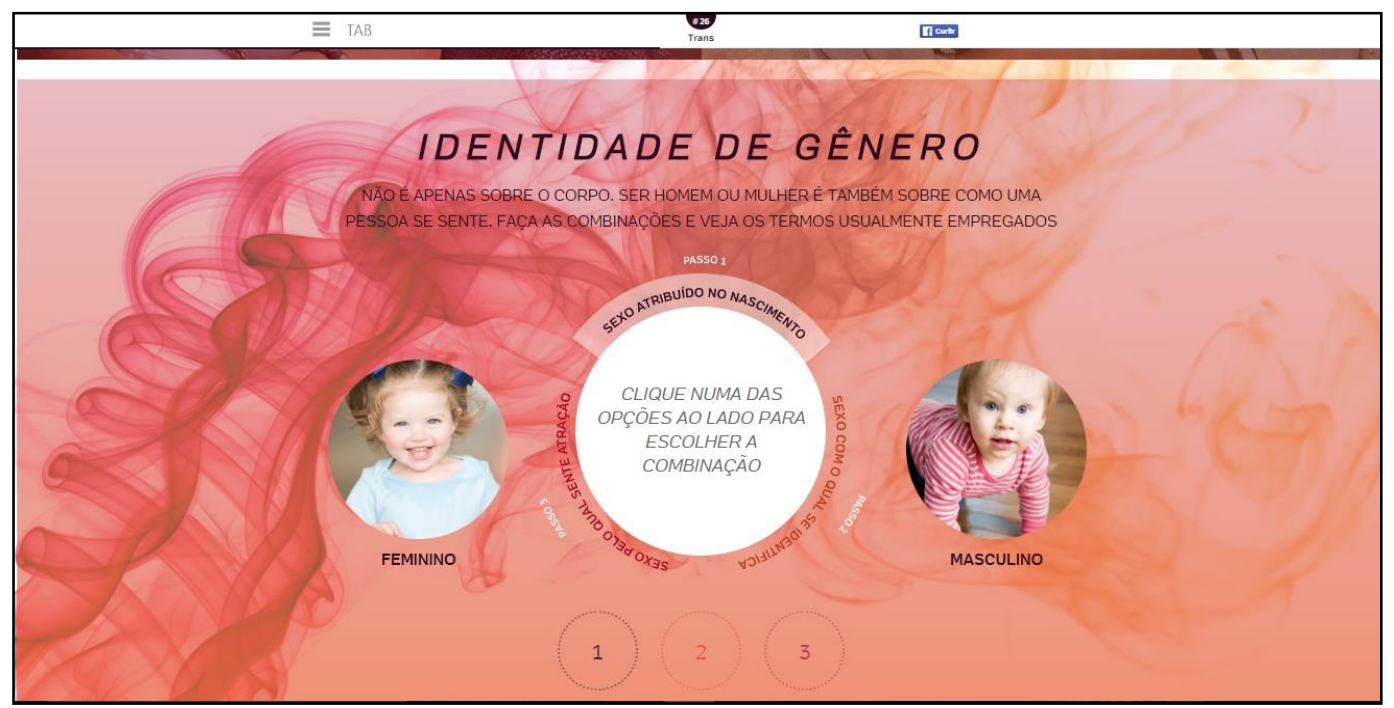

Figura 4. A informação é mostrada em uma espécie de infografia animada interativa, que se torna um diferencial quando se compara a mesma informação disponibilizada somente em texto.

Fonte: captura de tela. 
O leitor pode refazer a experiência diversas vezes e também pode, se quiser, ir direto para o link que mostra todas as possibilidades de termo utilizados. Além desses, vários outros exemplos evidenciam que a produção do $\mathrm{TAB}$ busca alternativas multimidiáticas e interativas para construir narrativas jornalísticas especiais, com o aprofundamento da reportagem.

O fato de existirem profissionais na equipe de produção que têm conhecimentos de $U X$ design certamente tem muito a ver com a criatividade e a originalidade com a qual a informação é disponibilizada. UX vem de User Experience, ramo do design cuja função, em diversas áreas, é garantir a melhor experiência de interação com o produto em questão - neste caso, reportagens acessadas via computador ou dispositivos móveis. Para o TAB, como se pode perceber, layout e conteúdo são igualmente essenciais para o sucesso de cada narrativa.

\section{CONSIDERAÇÕES}

Se o jornalismo se encontra em um momento de mudanças estruturais, em que a produção e o consumo de notícias são transformados, bem como o perfil do jornalista, levando-se em consideração as características da profissão e as novas formas de relacionamento com o público, isso ocorre porque a sociedade também passa por mutações significativas. A imprensa faz parte de um dos diversos campos sociais que se relacionam entre si e todos, em maior ou menor grau, acabam por sofrer influências das novas tecnologias de informação e comunicação.

Tais cenários são construídos devido a conjunturas diversas, de ordem econômica, social, cultural e tecnológica - e, como intencionou-se demonstrar neste artigo, fazem parte do momento de mudanças no jornalismo, que aos poucos está aprendendo a lidar com os novos hábitos de consumo de informação da população. Com tais mutações, surgem novos formatos jornalísticos, como as vertentes da reportagem: a grande reportagem multimídia, a reportagem paralaxe e/ou a reportagem multimídia interativa. São denominações de formatos semelhantes, cujas heranças da grande reportagem do impresso são notáveis, mas apresentam avanços significativos em relação à experiência de leitura do texto, agora interativa. A narrativa, aprofundada, intensa, liberta das técnicas redacionais canônicas da notícia, é enriquecida pela experiência interativa existente nos vídeos, nas animações, nos testes e outros recursos que estão em concordância com o leitor da era de convergência midiática. Este leitor, imersivo (SANTAELLA, 2004), tem todas as ferramentas para se aprofundar e construir sua própria ordem de leitura em reportagens como as publicadas pelo Uol na série 
TAB. Cada vez mais presentes no webjornalismo, essas novas narrativas apostam em layout e interatividade, elementos que comprovadamente envolvem os usuários a permanecerem por mais tempo na página web e a realizarem a leitura de caráter imersivo, conforme estudos empíricos de Sundar (2000 apud DEUZE, 2003).

McLuhan (2009) já dizia que, no momento em que os meios se encontram, ocorre uma libertação e liberação do entorpecimento e do transe que tais meios impõem aos nossos sentidos. Assim, apesar de estar presente apenas na quarta geração do webjornalismo, tal tipo de reportagem é a prova de que a Internet, como meio híbrido, pode e deve ser um espaço onde se pode ir além do convencional no jornalismo. Sua consolidação certamente depende de investimentos pesados em equipes multimídia, mas sua presença pode resultar em credibilidade à empresa jornalística, característica desejada na imprensa; e inovação, valor muito buscado no ambiente corporativo.

Por fim, vale dizer que a reportagem digital é um gênero onde a figura do jornalista como intermediário se mostra ainda mais importante, uma vez que exige dedicação, investigação e amplitude informacional. A qualidade desses produtos corrobora o que Wolton (2010, p. 72) defende: quanto mais informação acessível e gratuita, e mais liberdade para cada um fazer o que quiser, mais será imprescindível o jornalista para "selecionar, hierarquizar, verificar, comentar, legitimar, eliminar e criticar".

\section{REFERÊNCIAS}

ANDERSON, Chris; BELL, Emily; SHIRKY, Clay. Jornalismo pós-industrial: adaptação aos novos tempos. Revista de Jornalismo ESPM, v. 5, p. 30-89, 2013.

ANDERSON, Kevin. Beyond the article: frontiers of editorial and commercial innovativon. Reuters Institute for the Study of Journalism. Universidade de Oxford: 2017.

BARBOSA, Suzana. Modelo JDBD e o ciberjornalismo de quarta geração. Grupo de Pesquisa em Jornalismo On-line. FACOM-UFBA. 2008. Disponível em:

<http://www.facom.ufba.br/jol/pdf/2008_Barbosa_RedUCMx.pdf>. Acesso em: 2 jan. 2017.

BARBOSA, Suzana. Jornalismo convergente e continuum multimídia na quinta geração do jornalismo nas redes digitais. Notícias e Mobilidade. O Jornalismo na Era dos Dispositivos Móveis. Covilhã, PT: Livros LabCOM, p. 33-54, 2013.

BARSOTTI, Adriana. Transformações contemporâneas nas práticas jornalísticas: o jornalista on-line como mobilizador de audiência. Revista da Associação Nacional dos Programas de Pós-

Graduação em Comunicação | E-compós, Brasília, v.17, n.1, jan./abr. 2014. 
BELL, Emily; OWEN, Taylor; BROWN, Pete; HAUKA, Codi; RASHIDIAN, Nushin. The Platform Press. How silicon valley reengineered journalism. Tow Center for Journalism. Columbia Journalism School: 2017.

BENETTI, Márcia. Revista e jornalismo: conceitos e particularidade. In: TAVARES, Frederico de Melo; SCHWAAB, Reges. (org.). A revista e seu jornalismo. Porto Alegre: Penso, 2013.

BRUNS, Alex. Gatewatching: collaborative online news production. New York: Peter Lang, 2005.

CANAVILHAS, João. Webjornalismo: considerações gerais sobre o jornalismo na web.

Comunicação apresentada no I Congresso Ibé-

rico de Comunicação. 2001. Disponível em < http://www.bocc.ubi.pt/pag/canavilhas-joao-

webjornal.pdf >. Acesso em: 2 jan. 2017.

Webjornalismo: Da pirâmide invertida à pirâmide deitada. 2006. Disponível em

< http://www.bocc.ubi.pt/pag/canavilhas-joao-webjornalismo-piramide-invertida.pdf >. Acesso em: 2 jan. 2017.

A reportagem paralaxe como marca de diferenciação da Web. In: Paula Requeijo

Rey y Carmen Gaona Pisonero, Contenidos innovadores en la Universidad Actual, p. 119-129.

Madrid: McGraw-Hill Education, 2014.

CASTELLS, Manuel. A Sociedade em Rede. $2^{\text {a }}$ ed. São Paulo: Paz e Terra, 1999.

COSTA, Caio Túlio. Um modelo de negócios para o jornalismo digital. Revista de Jornalismo ESPM, v. 9, p. 51-115, 2014.

DEUZE, Mark. The web and its journalisms: considering the consequences of different types of newsmedia online. New Media \& Society: London, Vol. 5 (2), p. 203-230, 2003.

FREITAS, Bruno; ALMASRI, Omar. O Futebol no Inferno. TAB. Edição 21. 2015. Disponível em: < http://tab.uol.com.br/futebol-iraque/>. Acesso em: 5 maio 2015.

ITO, Liliane de Lucena; VENTURA, Mauro de Souza. A Reportagem Multimídia Interativa: Inovação, Produção e Monetização. Brazilian Journalism Research, vol. 12, n. 13, p. 134-151, 2016.

JENKINS, Henry. Cultura da Convergência. Tradução de Susana Alexandria. São Paulo: Aleph, 2008.

JORGE, Thaís de Mendonça. Gêneros Emergentes no Jornalismo. Revista Contra\&Dição, ano 1, v. 1, 2008. Disponível em: < http://bit.ly/2ibQJIl >. Acesso em: 2 jan. 2017.

LENZI, Alexandre. O desafio da produção de conteúdos noticiosos multimídia no cenário da convergência: a experiência dos repórteres do Diário Catarinense. Estudos em Jornalismo e Mídia Vol. $9 \mathrm{~N}^{\mathrm{o}}$ 1, p. 93-107, jan.-jun. 2012.

LIMA, Edvaldo Pereira. Páginas ampliadas: o livro-reportagem como extensão do jornalismo e da literatura. $4^{a}$ ed. São Paulo: Manole, 2009.

LONGHI, Raquel. O turning point da grande reportagem multimídia. Revista Famecos: Porto Alegre, v. 21, n. 3, p. 897-917, set-dez 2014.

MCLUHAN, Marshall. Os meios de comunicação como extensões do Homem. 16 ${ }^{\mathrm{a}}$ ed. Tradução de Décio Pignatari. São Paulo: Cultrix, 2009. 
MIELNICZUK, Luciana. Características e implicações do jornalismo na Web. 246f. Teste (Doutorado em Comunicação e Cultura Contemporânea). Universidade Federal da Bahia, Salvador, março de 2003. Disponível em:

<http://www.facom.ufba.br/jol/pdf/2001_mielniczuk_caracteristicasimplicacoes.pdf $>$. Acesso em: 2 jan. 2017.

PAVLIK, John. Journalism and new media. New Youk: Columbia University Press, 2001.

PEREIRA, Fábio Henrique; ADGHIRNI, Zélia Leal. O jornalismo em tempos de mudanças estruturais. Intexto: Porto Alegre, v. 1, n. 24, p. 38-57, 2011. Disponível em:

<http://seer.ufrgs.br/index.php/intexto/article/view/19208 >. Acesso em: 2 jan. 2017.

SANTAELLA, Lucia. Navegar no ciberespaço: o perfil do leitor imersivo. São Paulo:

Paulus, 2004.

SCALZO, Marília. Jornalismo de revista. $4^{\mathrm{a}}$ ed. São Paulo: Contexto, 2011.

VENTURA, Mauro de Souza; ITO, Liliane de Lucena. Inovação no webjornalismo: dinâmica empresarial, arranjos produtivos e novos formatos. Contemporânea - Revista de Comunicação e Cultura, v. 15, n. 1, p. 81-100, 2017.

WOLTON, Dominique. Informar não é comunicar. Porto Alegre: Sulina, 2010.

Original recebido em: 14 de fevereiro de 2017

Aceito para publicação em: 7 de novembro de 2017

Liliane de Lucena Ito

Doutora em Comunicação pela Universidade Estadual Paulista (Unesp).

Mestra em Comunicação e jornalista, também pela Unesp.

Esta obra está licenciada sob uma Licença Creative Commons. 